\title{
The use of an online support group for neuromuscular disorders: a thematic analysis of message postings.
}

\author{
Oonagh Meade ${ }^{1}$, Heather Buchanan ${ }^{2} \&$ Neil Coulson ${ }^{2}$ \\ ${ }^{1}$ School of Health Sciences, University of Nottingham, Nottingham, United Kingdom \\ ${ }^{2}$ School of Medicine, University of Nottingham, Nottingham, United Kingdom
}

Corresponding Author:

Oonagh Meade, B42 School of Health Sciences, University of Nottingham, Queens Medical Centre, Nottingham, NG7 2UH, United Kingdom. Phone: +44 011582 30541, Fax: +44 0115 82 30220. E-mail: oonagh.meade@nottingham.ac.uk

Keywords: online forum; peer support; member interactions; qualitative analysis; NMDs; rare illness.

\footnotetext{
Abstract

Purpose: People affected by neuromuscular disorders can experience adverse psychosocial consequences and difficulties accessing information and support. Online support groups provide new opportunities for peer support. The aim of this study was to understand how contributors used the message board function of a newly-available neuromuscular disorders online support group.
}

Methods: Message postings $(n=1,951)$ from the first five months of the message board of a newly-formed online support group for neuromuscular disorders hosted by a charitable organisation were analysed using inductive thematic analysis. 
Results: Members created a sense of community through disclosing personal information, connecting with people with similar illness experiences or interests, welcoming others, and sharing aspirations for the development of a resourceful community. Experiences, emotional reactions and support were shared in relation to: delayed diagnosis; symptom interpretation; illness management and progression; the isolating impact of rare disorders; and the influence of social and political factors on illness experiences.

Conclusions: This study provided a novel insight into individuals' experiences of accessing a newly-available online support group for rare conditions hosted by a charitable organisation. The findings highlight how the online support group provided an important peer support environment for members to connect with others, exchange information and support, and engender discussion on political and social issues unique to living with often-rare neuromuscular disorders. Online support groups may therefore provide an important and easily accessible support outlet for people with neuromuscular disorders as well as a platform for empowering members to raise awareness about the impact of living with these conditions. Further research is needed to examine member motivations for using such groups and any effects of participation in greater detail.

\section{Introduction}

Neuromuscular disorders (NMDs) is an umbrella term used to characterise disorders which are "caused by a dysfunction of a component of the motor unit (the motor nerve and the muscle it controls)" [1, pg. 2]. Some NMDs are genetically inherited whilst others are acquired. The most prevalent groups of NMDs are hereditary neuropathies, disorders of the neuromuscular junction, myotonic disorders and muscular dystrophies (comprising 32\%, 14.7\%, 13.3\% and $12.6 \%$ of the total number of people affected by NMDs respectively) [2]. The most prevalent specific types of NMDs include Hereditary Motor and Sensory Neuropathy, Myotonic 
Dystrophy, mitochondrial disorders, dystrophinopathies (including Duchenne Muscular Dystrophy and Becker Muscular Dystrophy), Facioscapulohumeral Dystrophy, Limb Girdle Muscular Dystrophy and Spinal Muscular Atrophy [3]. While the prevalence of NMDs is significant (70,000 people in the U.K.), many NMD types are rare disorders [2]. Despite ongoing genetic research, there are no cures. Symptoms and progression vary, but common symptoms include a decline in: muscle strength [4,5]; activities of daily living [4,6]; ambulatory ability [4,7]; gross and fine motor skills [6]; and lung capacity and cardiac health [5].

Individuals with NMDs can experience psychological challenges, including feelings of loss of control, grief or uncertainty about the future [8,9], stigma in relation to physical manifestations of their illness $[7,10]$ and difficulties dealing with familial genetic risk $[8,9]$. People with NMDs have been found to experience a higher prevalence of depressive symptoms [11] and lower quality of life than healthy controls [12]. Negative impacts on social participation $[4,6]$ and interpersonal relationships have also been reported. Family members who care for those with NMDs can also experience multiple stressors including: difficulties and/or delays in getting a diagnosis [13,14]; exhaustion [14]; worries about disease progression [15-17]; and a need to fight for resources, information and support services [14]. Elevated parental stress [18,19], and higher depression and distress [20] have been reported among NMD carers.

Both individuals affected by NMDs [21] and their family members $[15,16]$ have emphasised the importance of social support in terms of coping and mediating stress. Higher levels of social support have been associated with better psychological health among people with NMDs $[22,23]$. However, studies on the use of support groups for NMDs are scant. One 
recent study by Hodges and Dibb (2010) examined parents' experiences of using a Duchenne Muscular Dystrophy support organisation. Being part of a support group for this condition allowed parents to feel a sense of belonging and empowerment and to gain valued advice and support. In return, giving advice to other parents helped them to feel a sense of purpose and enjoyment. Whilst there are limited studies on social support interventions for people with NMDs, results from an evaluation of a multi-component rehabilitation intervention for people with NMDs demonstrate that members valued the peer support aspects of this programme (having the opportunity to meet others with their condition, and feeling part of a community and less lonely in their experiences) [24]. Similarly, those with muscular dystrophy taking part in an exercise intervention also cited contact with other people with similar conditions as one of the main benefits of participation [25]. These results are also consistent with the findings of a study which evaluated participants' experiences of attending a specialist neuromuscular centre [26]. Members valued the opportunity to meet others socially, develop their knowledge from meeting others with the condition and learn from others about ways of coping. It is clear from these studies on support interventions in NMDs that people affected by NMDs and their carers may value the social opportunity to interact with others facing similar situations and share informational support, as well as advice, about coping with an NMD.

Health-related online support groups have gained prominence as a source of social support and may be useful to people affected by NMDs and their carers due to the rarity of these conditions and the difficulties people may have in meeting others affected by similar disorders. Online support groups have a number of advantages in terms of accessing support, including: the availability of information and support at any time [27,28]; the accessibility of support from home (which may be advantageous for those with limited mobility) [29]; and 
the lack of geographical boundaries to meeting a diverse support network [28]. This medium also offers anonymity for disclosing sensitive information [30] and allows people to choose whether to actively participate or 'lurk' and read online communications [31]. Potential disadvantages of online support groups include: 'flaming' or verbal harassment [32]; reading about other members' illness progression [33]; dealing with support group activity that is too high [27] or too low [34]; and variable quality of medical information [35]. However, analyses of online support group postings have revealed that the majority of messages are not erroneous or harmful $[36,37]$ and analysis of message posts have been used to demonstrate the social support $[34,38]$ and self-help $[39,40]$ therapeutic functions of such groups.

Online support groups may provide one of the only mechanisms for people affected by rare diseases (such as NMDs) to meet people with similar experiences [41] and there is limited research exploring how people affected by rare diseases use such groups [42]. These groups may be more accessible for people with NMDs and their carers when compared with other services. For example, accessing an online support group may be easier for those with physical disabilities than traditional face-to-face groups $[38,41]$. Such groups may also be beneficial for carers, who may have difficulty accessing face-to-face support groups due to their caring commitments. Online support groups also have the potential to provide members with 24 -hour access to support, and the lack of geographical boundaries allows members to access a wider, more diverse support network [41,43]. This may be particularly important in NMDs, as rare conditions may limit individuals' abilities to meet others who have experience of the same condition.

Previous research in the U.K., in which families of children with Duchenne Muscular Dystrophy were given a computer with internet access, indicated that there were positive 
effects of internet access on both family relationships and on the child's feelings of isolation [44]. There is preliminary evidence that families affected by NMDs have started to use online support groups in relation to the condition, and that parents value the contact with other families of children with NMDs as a peer support system [16]. There is currently no available research on how people with an NMD or their family members use such groups. The aim of this study was to understand how contributors used the message board function of a newly-available NMD online support group. To achieve this aim, a qualitative inductive thematic analysis of messages posted to a new online support group was undertaken.

\section{Methods}

\section{Data collection}

Data were collected from a publicly-accessible, U.K. based message board, on an online support group for people affected by NMDs. This online support group was hosted by a charitable organisation that supports individuals and families affected by NMDs. The group is moderated by volunteer moderators with lived experience of NMDs who were recruited via interviews with the charity. Moderators check initial posts by new members before allowing them to be posted on to the online support group forum. Charity staff members also contribute to the group through news items (e.g. developments in research, campaign work, and volunteer opportunities).

All message postings from the first five months of the group $(n=1,951)$ were collected and indexed into a catalogue so that messages could be analysed holistically in the context of message threads or conversations [45]. Analysis of messages posted to this new online support group (one of the first of its kind for people with NMDs in the U.K.) during its first five months of operation provided an opportunity to explore both initial and more developed 
conversation threads in real-time. The included messages were the product of 270 distinct conversation threads from a total of 144 group members.

\section{Ethical considerations}

Ethical approval was obtained from the Institute of Work, Health and Organisations' departmental ethics committee at the University of Nottingham. As the online support group did not require a membership log-in, and in line with similar studies (e.g. $[43,46])$, it was not deemed necessary to gain informed consent for the analysis of message postings. To protect the identity of individual members of the group, all identifiable member information (e.g. names, usernames, age, type of diagnosis, etc.) and the online support group name were removed from the analysis.

\section{Data Analysis}

Due to the lack of literature examining communication between members on online support groups for people with rare disorders, data were analysed using an exploratory, inductive, data-driven approach. Thematic analysis is a method that is applicable across a range of epistemological positions and in this study, a realist/essentialist theoretical approach was adopted in this analysis whereby the message posting content was examined at a semantic level [47]. Thematic analysis guidelines described by Braun and Clarke [47] were followed. These guidelines provide comprehensive steps for researchers wishing to describe, organise and report patterns in qualitative material and were well-suited to the authors' aim of understanding how contributors used the message board facility on this online support group.

Initial analysis involved reading and re-reading the entire message posting data set several times. This was an "active" reading, in which the first author continuously made notes on initial impressions of and emergent patterns in the data [47]. Braun and Clarke [47] outline two approaches to this initial reading phase: one in which the reading is informed by theory and 
interprets data in relation to theory; and a converse approach in which the data set is the sole source of meaning. In the current research, the reading phase would be more accurately described as data-driven with a theoretical undertone. Given that the authors had engaged with relevant research prior to data analysis, becoming exposed to relevant theory, initial readings of the data may have been coloured by this prior knowledge. However, the analysis remains rooted primarily in the data as is displayed in the data-driven process of thematic analysis detailed below.

In line with the data-driven approach, the initial reading phase was repeated several times to allow the first author to become familiar the data before beginning code generation. After the initial reading phase had been completed, the code-generation phase of analysis began. This second phase involved organising and interpreting the data at a basic level, breaking it down into workable segments. The entire data set was coded manually. The first author assigned descriptive/interpretive codes to as much of the data as possible, often assigning multiple codes to the same segment. These codes were collated and an exhaustive list was made of all codes.

The next analytic step refined this large index of codes. Each code was written on a separate, small piece of paper and sorted into "theme-piles" [47, p.89]. This process was not linear in nature, often requiring the researcher to rework and rethink thematic groupings. It was also recursive in that codes were sourced back to the data from which they were derived, in order to ensure analytic rigour and connection with the data. Some codes did not fit naturally into a thematic category and so were sorted into a 'Miscellaneous' theme-pile. At this point, the major theme-piles (themes) were identified, as well as smaller piles (sub-themes) that were related to but not subsumed by each other. An effort was made, at this stage, to work the 'Miscellaneous' codes into the major theme-piles, while remaining open to new thematic formations. Not all 
miscellaneous codes were worked in to the theme piles and some were discarded. Iterations of the thematic map were discussed and refined with the second and third authors before a final thematic map was agreed.

A final analytic step involved further refining of the themes and their sub-themes. The researcher referred back to the data again, to ensure that the raw material fed in to the emergent codes, sub-themes and themes in a consistent way that was true to the original posting material. It was also ensured that each theme and sub-theme comprised enough raw data to warrant a theme or sub-theme. At this stage, a thematic map of the analysis was drafted, including a list of themes, sub-themes and codes within the sub-themes. Considerable efforts were made at each stage of this process to ensure that the emerging analysis was rooted in the available data and reflected the experiences of the support group's members.

\section{Results}

Three over-arching themes were identified: Connecting and sharing; 'An understanding audience'; and Recognition and awareness. These themes with their corresponding subthemes and codes are illustrated in Table 1. In the message extracts below, square brackets (i.e. [ ]) are used to denote where identifiable information has been removed. A double ellipsis (i.e. .....) is used to indicate where text has been removed for the purpose of brevity. Underlined text indicates where a member included a hyperlink to a webpage in their postings. Original typographical errors within some quoted message extracts remain uncorrected. The analysis presented below includes relevant example quotations from 41 distinct members, and is representative of the conversations comprising the entire dataset. For clarity, each individual quoted below is given a unique identifying number (1-41) which is included in brackets after their quoted excerpt(s). 
'Insert table 1 about here'

\section{Connecting and sharing}

This theme describes how initial connections were forged between members in this newlyformed online support group and is presented under three main sub-themes; 'establishing common ground', 'sharing diagnosis experiences' and 'sharing diagnosis support'.

\subsection{Establishing common ground}

New members often introduced themselves by disclosing personal information (e.g. age, diagnosis or carer status, current/past occupations, etc.):

Hello. I'm a [age] year old father, husband and all round bad son-in-law (you have to annoy someone) who shares a body with [type of muscle condition]......I work in [job area] (meaning not a lot but it sounds impressive), living in [place name]. I have 3 children. (1)

Members often stated their wish to connect with, and learn from, others who were at a similar stage of diagnosis or those with similar NMD types:

I've just joined and was wondering if there is anyone else here with the same condition as myself. I have been told it's rare and I thought it would be good to speak to anyone who has any knowledge of this condition. (2)

In response to posts from new members, existing members shared diagnoses, symptoms or experiences and initiated further conversations, noting the availability of support for new members from other knowledgeable members. Existing members, especially group moderators, shared information on how to use the board. They also encouraged newcomers to enjoy and contribute to the online discussions by encouraging them to post messages both in relation to NMD and more social topics: 
Post away with anything that is on your mind, whether it be the biased judging on Strictly Come Dancing, issues regarding your [condition type] life experience or concerns following the latest Government (dis)incentives. (3)

New members were also encouraged to ask questions and were assured of the friendliness and helpfulness of others and the availability of support from forum members:

We're a friendly bunch here. (4)

I'm happy to answer any questions if anyone wants to $\mathrm{PM}^{1}$ me. (5)

Finally, new members expressed enthusiasm about joining the group and gratitude for its informative and welcoming environment. Members shared aspirations about the group developing into a "powerful resource" (6) based on their personal expertise and a community of people who understand the "niggly things without huge explanation" (7):

We're all experts in our own little ways and together we've got lots of useful knowledge. (8)

In addition to sharing aspirations about the development of a resourceful community, members also shared their aspirations towards the group becoming a social space to connect with others with NMDs. Some members specifically mentioned that they hoped to make friends through joining the forum:

I would like to widen my circle though so thought I would give this site a go. (7)

\footnotetext{
${ }^{1} \mathrm{PM}$ is shorthand for private message, which members could use to communicate privately with one another.
} 
In terms of members' aspirations for a fun and social forum, some members started social discussions based on their hobbies and interests. Similarly, the group moderators also initiated specific threads on jokes, games, pet photographs, etc.:

Post pictures of your pets or if you don't have any your favourite cute animals.

Here's one of my cats, [pet's name].......he's behind you! (8)

\subsection{Sharing diagnosis experiences}

Diagnosis experiences formed an important part of initial discussions. As mentioned earlier, forum users regularly introduced themselves by describing their particular type of NMD diagnosis or their family member's diagnosis, often followed by a description of how this affected them. For those who mentioned that they did not have a diagnosis, they sometimes described the most recent suggestion from doctors about what their condition might be, or they simply described how their condition currently affected them:

My son is [age] and has an undiagnosed [condition type] affecting his legs and arms mostly. (9)

Members shared common experiences of 'diagnostic delay'. For members who had later-onset NMDs, factors contributing to delay included a lack of realisation of the abnormality of symptoms. For example, one member described how he used to feel proud of his large calves, only to later discover that this was a symptom of his condition:

Instead of them being something to be proud of, it was pseudo hypertrophy, one of the indicators of my condition. (10)

For others, personal factors such as denying their symptoms or feeling too proud to seek medical advice influenced their delay in getting their symptoms checked out: 
I am a relatively private person when it comes to medical problems so I didn't really say to anyone about it. (11)

Delays in having symptoms recognised or taken seriously by medical professionals and in accessing specialist referrals were also commonly discussed:

It took me six years and many referrals to psychiatrists before I found a neurologist who would believe me and test me. (12)

Members discussed how they experienced a range of negative emotions in relation to diagnosis including shock, uncertainty, loss and sadness:

Just diagnosed with [disease type]. Not really sure what to think or do (13).

I'm a carrier of [disease type] and have 2 boys who are affected aged [age] and [age]. Struggling to come to terms with it all - it's still very raw. (14)

For some members, these feelings were compounded by a sense of feeling unsupported or isolated:

It [child's diagnosis] left my wife and I feeling empty. There is seemingly very little support. (15)

Some members discussed the sense of "relief to finally have a proper diagnosis" (7) when they eventually received recognition of their symptom experiences in the form of a diagnosis, especially if they were waiting for a long time for this. Their diagnosis often came after receiving a referral to a specialist who had more knowledge about their condition:

I now have a great neurologist who believed me and did the appropriate tests. (12)

\subsection{Sharing diagnosis support}


One of the ways in which the online community helped others was by validating their experiences of diagnosis by noting inherent commonalities in diagnosis experiences. This validation was also often apparent when members noted similar experiences of delayed diagnosis:

I think you'll find that other members will relate to your story of how long it took to get diagnosed as many have experienced this too. (4)

Members often drew on personal experience to reassure others that their feelings regarding diagnosis were normal. This included reassurance about how normal it is to feel shocked or overwhelmed by the diagnosis:

Hi [username], welcome to the forum. 4 weeks ago is a very recent diagnosis, I'm not surprised you are still in shock. Best wishes to you and your family at this difficult time. The shock will wear off as you start to come to terms with the diagnosis. Sites like this can certainly help as there will be people who know what you are going through who will be able to offer support. (16)

As well as validating experiences and emotions related to diagnosis processes, forum users also provided words of comfort and reassurance to others going through the process. This support varied, but most often included the expressions of sympathy or sadness at member diagnoses:

I'm sad to hear about your sons' diagnoses, I know it's very upsetting when you find out that one's children are affected. (17)

Members also offered encouragement to others in coming to terms with a diagnosis. For example, one member encouraged another not to let the diagnosis label affect their outlook:

Just make the best of what you've got. Forget the name tag and don't let it get down and life goes on as you are still you..! (18) 
Furthermore, members drew on their own personal experience to reassure others of the benefits of getting a proper diagnosis. They encouraged members not to dwell on the negative aspects of the diagnosis, but to think in terms of the positives of gaining access to better medical and social care services support:

[The diagnosis] ended years of not knowing and unlocked so much help that I look back on it with pleasure. Within two days $\mathrm{CS}^{2}$ had visited my home and assessed the situation and arranged for specialists to help me, falls Prevention Service, two different sets of O.T.' ${ }^{3}$, speech and language therapists, dieticians, physiotherapists. (19)

Recently diagnosed members were encouraged to take time to get used to the diagnosis and seek out support from fellow support group members, support organisations and clinicians in order to help them cope:

There are a few message board members on here with [disease type] and once you have had time to absorb what you have been told you will find that there are people, resources and support to help you manage and adapt. (6)

Don't know where you live but go to your GP 4 get a referral to [doctor's name] at [hospital name]. He is the best. (20)

\section{2. 'An understanding audience'}

\footnotetext{
${ }^{2}$ CS stands for Community Services.

${ }^{3}$ O.T.'s refers to Occupational Therapists

${ }^{4} \mathrm{GP}$ refers to General Practitioner
} 
Members used the board to discuss symptoms and coping with others who understood their experience. The sub-themes 'collective symptom interpretation', 'emotional reactions to symptoms' and 'supporting one another with condition management' illustrate this theme.

\subsection{Collective symptom interpretation}

A common feature of introductory messages was the detailed description of symptoms, with some users starting specific symptom-related threads. As well as describing symptoms, the impact of symptoms on daily life was presented. Symptoms often had an adverse impact on everyday activities, including social and work activities:

I worked with the [workplace] as a [job title] until I got ill health retirement last September, and although I really miss my work ...... I knew I wasn't coping with the computer, walking stairs etc. (21)

Members commonly sought feedback, often to verify the normality of their symptoms. A common issue was the struggle to find others affected by a similar condition with whom to compare symptoms. This made the following member fearful as she could not anticipate how her symptoms would progress:

I'm so scared what's going to happen. I can't lift a drink without it spilling and other things, I've been looking to see if I can find anyone like me and see what has happened to them but I can't find them. (22)

Others wanted to know if their symptoms were typical of a specific NMD condition and appealed for information:

I would like to find out if these symptoms are typical of [specific condition]. Your help will be much appreciated. (23) 
Members offered opinions and asked questions to help tease out answers to queries. Sometimes the information shared was grounded in members' experiences of similar problems:

Have you been for respiratory lung function test???...... the reason I ask is that I use a ventilator when I sleep but pre ventilator I had constant morning sore head, lots of nose bleeds and ended up sleeping sitting up for about a year. (24)

However, users were cautious about how others interpreted advice and often encouraged others to seek out professional expertise:

I'm not a doctor and would urge you to discuss your concerns with a neurologist, but in a purely personal opinion I'd say it was normal for someone to experience frequent chest infections. (25)

\subsection{Emotional reactions to symptoms}

Feelings of symptom-related worry were commonplace, including concerns about the nature and likely impact of symptom progression:

I'm a bit concerned about my heart (which I understand is typically affected/weakened by [specific condition]). My symptoms are a feeling of being very aware of my heartbeat (particularly in bed) and slightly trembly type feelings. Another symptom is that I seem very easily surprised by noises, particularly at night. My heart occasionally aches, but it's more a feeling of the presence of my heart. I also seem to get pins and needles at night in my arms. It's all rather worrying of course, and this could be affecting how I feel. (17) 
Access to formal support and criteria for disability benefits in order to deal with symptoms and symptom progression was also a source of concern expressed by members. For example, one woman expressed concern about her family's financial future if her husband needed to stop working due to his symptoms. Her worry was compounded by uncertainty about where to access information on benefits and entitlements:

So now comes the help/advice I need ...... does anyone know what benefits or entitlements he might be able to claim he currently gets DLA ${ }^{5}$ and Carers allowance but that's all ...... Any advice would be a really big help as we don't know where to start. I am looking at getting job as the children are a little bit older now so that he can give up work but making that move with no financial backup is a worry. (26)

Regret and frustration relating to declining capacity to partake in activities (e.g. work, social and sexual activities) and lost independence were noted by many members:

I hate this. I can't go out to parties because I can't hold a cup or wear heels. (22)

I would dearly love to be sexually active, it's one of my greatest sources of sadness. (27)

This decline in activities led to a sense of isolation for some members.

Worst aspect of the condition? The feeling of isolation I think gets to me most.

Also, some members felt that the lack of medical treatment compounded their sense of isolation when managing symptoms.

\footnotetext{
${ }^{5}$ DLA is an acronym for Disability Living Allowance.
} 
I don't ask the impossible but I do expect a modicum of medical management. (3)

Members often discussed aids and adaptations they were using or considering using (e.g. crutches, wheelchairs, car/home adaptations, etc.) which was an emotive topic. Many members expressed their wish to stay as independent as possible, and described difficult decisions to use assistive devices/services. While this determination not to use adaptations or aids was often motivated by trying to maintain independence, it was also influenced by concerns about other people's perceptions of such devices/adaptations:

With my muscle disease seemingly catching up with me I did opt for a Blue Badge and Motability ${ }^{6}$. My pride took a bashing but it was that or me (literally).

I was slowly losing confidence and falling more, still can't bear to be seen with them [crutches] but that's life. (10)

Although forum users often discussed negative aspects of their symptoms, they also expressed a desire to maintain a positive outlook on dealing with their condition. Some noted their deliberate attempts to remain positive about their condition in order to help themselves to cope better:

A positive mental attitude is the best way to cope with $\mathrm{MD}^{7}$, so my motto is to 'Keep Smiling' whatever life throws at you. (30)

\footnotetext{
${ }^{6}$ A Blue Badge refers to a U.K. based parking scheme which allows people with mobility problems to park in restricted parking areas. Motability is a scheme which allows people with a disability to lease a car, powered wheelchair or scooter using a Government-funded mobility allowance.

${ }^{7} \mathrm{MD}$ refers to Muscular Dystrophy
} 
Different personal perspectives were discussed in terms of dealing with any challenges related to their condition. Some advocated taking a day-by-day approach to the management of symptoms, while others opted to take a prepared approach to anticipating problems related to their condition:

I feel the best rule for me is to ignore things until they really need looked at, one day at a time. (24)

My condition is getting worse and it now means the small adaptions I once made are becoming huge adaptions that I'm not always ready to make! I'm getting there though and trying to face it all head on. (7)

Another way in which forum users demonstrated a positive outlook was to note how lucky they felt to have less severe symptoms than others:

It seems like [specific condition] covers a broad spectrum and I am probably quite lucky like you and your brother to be still mobile at [age], even if a little wobbly these days. (10)

A positive outlook on one's symptoms was also evident in the frequent use of humour when describing specific issues. For example, the following member joked about the number of falls he had taken recently and the unfortunate circumstances in which they had occurred:

I have started to trip up over nothing and taken a few tumbles. These tumbles always seem to happen when I am in a crowded place or walking past a nice young lady or when the ground is hard. Now why is that? It is never at home on the nice soft carpet in front of the cat! (11) 
While a common theme in members' discussions was a decline in social participation, the helpfulness of their family and close friends in supporting them through their condition was often noted:

I've got a great, supportive family, my circle of friends has got a bit smaller as I'm not able to get out and about as much but the ones I have are amazing. (7)

This experience was echoed by others who noted, for example, that friendship was a "quality rather than a quantity thing" (3).

\subsection{Supporting one another with condition management}

Board users tried to help each other to cope in several ways. Members shared experiences or advice on how they managed their condition. This included information about such topics as physiotherapy, chiropody, massage, healthy eating, exercise, using special pillows, footwear and ventilators:

I find massages help my circulation when I've had one. (4)

Information was also provided on services or information resources to help people cope with their condition, including securing disability benefits:

We have a thread on here about making sure you're getting all the benefits you're owed. Carers.org also have a section on their website with information about money and benefits that carers are entitled to. Hope this helps as a start. (8)

Members also validated each other's experiences and feelings related to symptoms by normalising symptom experiences and emotional reactions. Due to the variability in the 
condition types, and different experiences of disease progression, members reassured one another that symptoms would not be experienced by everyone in the same way:

As my condition as with other forms of [condition type] can be so variable between individuals it is difficult to compare notes. (25)

In response to members sharing similar experiences, a feeling of reassurance was often noted by those who felt uncertain about symptoms. Specifically, they felt relieved not to be the only one experiencing these symptoms and related difficulties:

Glad I'm not the only one with the dribble problem. (31)

It's reassuring to know that I'm not the only one who has problems in this weather!

Consistent with the support offered when new members initially joined the group, users of the group continued to offer support to others and assurance of the availability of informational and emotional support from fellow members in relation to living with NMDs. Forum users repeatedly reminded others that they were not alone in their experiences of NMDs and that support was available on the forum:

Sometimes it can be from faceless friends that you can get the greatest understanding. How many members of this forum will never meet, yet the bonds you create using the typed word is no less than any friendships you have offline, in fact at times the friendships online can actually mean more. (33)

Users also encouraged others to adopt a positive and proactive outlook to coping with their condition: 
Maybe we can all try and focus on the upside of things rather than the negative. I

do feel that for every closed door another one opens. (19)

When discussing symptoms, members often reassured others about the personal benefits and positive experiences they had derived from the use of adaptive devices/aids such as ventilators:

It can take a while to get used to using it but the pros outweigh the cons in my opinion. I had more energy and less headaches in the morning. (6)

Members of the online support group commonly reported experiencing difficulties in securing suitable adaptations and aids to help manage symptoms and as well suitable medical support. Drawing on their own personal experiences, members encouraged others to fight for any adaptations, aids or services that they currently needed. In response to one member's story about struggling to get funding for an accessible bathroom, another member noted her similar experience of struggling to get a suitable bathroom in her council accommodation. She then encouraged the other member to be persistent in getting their needs met:

Sadly your experience with your local council is not unique. I had to survive a couple of years of strip washing before my bathroom was converted......Keep on at your OT, local council and hospital peeps, hopefully someone will get hosed off being nagged at that you'll get success. (3)

\section{Recognition and awareness}

Members used the board to situate their illness experiences within the broader societal and political climate. The rare nature of many of the NMDs discussed contributed to this narrative. The sub-themes below illustrate how members used the board to: share difficulties 
they had with getting recognition for their condition; foster debate on current political, social and healthcare issues affecting those living with NMDs; and discuss and advocate awareness raising activities to boost the profile of NMDs.

\subsection{Sharing difficulties regarding NMD recognition}

Members often faced problems gaining understanding about symptoms and conditions from health professionals, which was problematic in terms of getting a diagnosis and accessing supportive treatment. This was often due to the rarity of conditions:

[Member's user name] made the point, a lot of our conditions are rare, unique and different. What is so obvious is that even the best specialists do not completely understand them. (19)

This lack of understanding presented problems for members, not only in terms of getting an initial diagnosis but also in terms of subsequent medical care:

My poor GP has very little knowledge of my case and it was only with my back up letters from the neurologist that allowed him to give me tablets for headaches.

This lack of understanding of their condition also caused difficulties in terms of dealing with social services professionals. One member reported his frustration at being recommended to apply for several jobs which were unsuitable for someone with his condition:

At least the Work Focus Interview Mafia are leaving me alone these days, it was a typical example of the "cream and park" system with them on the blower ${ }^{8}$ every other day with unsuitable jobs. (10)

\footnotetext{
8 "Blower" is a colloquial term for telephone.
} 
Misconceptions by the general public were also discussed. Members reported situations where they felt excluded from certain conversations/activities, due to perceived differences between disabled people and able-bodied people:

No one thinks of people with disabilities as sexual beings. We're not seen as being able to be in a relationship, let alone have sex! (35)

Members also reported difficulties in relation to people's reactions to their symptoms, which displayed a lack of understanding. This was particularly problematic for those members who were not displaying any overt or visible signs of disability, such as using a wheelchair:

I do think there is a bit of a "you're not in a wheelchair so you're not disabled" thing going on. (18)

Some members felt that discussions around welfare reforms in Government and the media misrepresented disabled people and contributed to a misunderstanding of the impact of living with disabling conditions such as NMDs. Feelings of frustration and disappointment about Government portrayals of disabled people were voiced:

One would have thought it was a very sombre moment announcing measures that would cause hardship to many thousands of disabled people. Instead Mr Osborne ${ }^{9}$ was smiling and receiving rabid cheering from the benches behind him...... say it shows no respect for the people affected. (19)

\footnotetext{
${ }^{9} \mathrm{Mr}$ Osborne refers to George Osborne who was the Chancellor of the Exchequer of the U.K. Government at the time the messages were posted.
} 
In terms of media coverage of these welfare cuts, one member felt that tabloid media were portraying disabled people as "lazy scroungers sponging off the state" (4). This type of media coverage provoked feelings of uncertainty and vulnerability:

Disabled people are being mercilessly slated by certain Right Wing sections of the media and I know from a different site how vulnerable and scared many of us are feeling lately. (10)

\subsection{Fostering discussion on political, societal and healthcare issues}

Members of the board, in particular volunteers or charity staff, often posted political, social or healthcare news items relating to living with NMDs to engender discussion about these issues:

[Charity director of research] has commented on potential research funding cuts ahead of the Spending Review announcement next week. What are your thoughts?

Members frequently discussed their concerns about welfare reforms and other political changes. Key concerns included the impact of new changes to the benefit system and work capability assessments:

If anyone has any ideas about how people with indefinite awards will be affected I'm sure we'd all like to know. (37)

In terms of welfare reforms, members also expressed anxiety that disabled people would be targeted unfairly or disproportionately by any benefit cuts, feeling that they may become soft targets for money savings and that benefit cuts could impact on their quality of life: 
I too find this worrying as without sounding hard done by the disabled seem to be being 'victimised' by government in their cuts..... These cuts worry me as my life at the moment runs smoothly, I am able to have care how I want, I'm able to go out when I like. If these proposed cuts were to go ahead I am suddenly going to find myself existing rather than living. (4)

While members mainly expressed concerns about proposed changes to benefit and health care systems, there was also some hope expressed that some changes, such as increasing General Practitioner control over service commissioning, may actually improve outcomes for members:

I have been involved in a lot of the politics of funding with my $\mathrm{PCT}^{10}$ and their inability to listen and understand my condition has been astounding at times. Regarding the proposed commissioning changes, I am hopeful but not yet convinced. (6)

\subsection{Raising awareness}

In order to raise awareness about NMDs, some individuals and families created blogs and personal websites:

We were one of only 12 families worldwide to be diagnosed with the dominant form of the condition, so I decided to set up a website about the conditions. (38) Contributors also posted educational content, including research items, to the board and reported educating people (e.g. health and social care professionals) as they encountered them. Members also encouraged each other to adopt expert roles in managing their own or their family members' conditions:

\footnotetext{
${ }^{10}$ PCT is an acronym for Primary Care Trust
} 
You are the expert on [son's name] condition, remind them of that and remind them that unless they have strong knowledge of [condition type] they'd do well to listen and learn. (3)

Contributors also noted how they had lent their support to and commended campaigns aimed at raising awareness of disability and NMD-related issues. For example, one member noted how he was feeling encouraged by news of a protest against Government cuts:

But it's really encouraging to hear about the protest on 3 October._It's about time politicians started listening to the people who are going to be most severely affected by the cuts. (10)

Members reported participating in awareness-raising meetings and conferences, surveys and petitions:

Signed and will be writing to M.P. ${ }^{11}$ on the subject. (39)

The [specific NMD type] Support Group UK will be at the [country name] Conference on Saturday, we're keen to get a regional group going in [country name]so if you're interested and want to find out more come over and say hello. (40)

An appreciation for volunteers who work to raise the profile of NMDs was also evident on the board and volunteer opportunities were advertised:

\footnotetext{
${ }^{11}$ M.P. refers to a Member of Parliament within the U.K. Government
} 
I'm the volunteer fundraising manager for the [charity name] in [country name].

I'd love to hear from anyone who is interested in getting involved in volunteering, joining one of our new local committees or doing any fundraising activity. (41)

\section{Discussion}

The aim of this study was to understand how contributors used the message board facility of a new NMD online support group. This was achieved by analysing the thematic content of message posts from the first five months of a newly-formed, publicly accessible online support group for this population.

The findings illustrate how members initiated and maintained conversations to create a resourceful and social community. In this context, as well as in other health-related online support groups [48, 49], self-disclosure was a key factor in developing and maintaining conversations. Most members disclosed their relationship to NMDs in their initial posts, emphasising the importance of this legitimisation when joining such groups [50, 51]. Members specifically sought out others with the same conditions or symptoms as them in order to compare experiences. This function may be particularly important for people with rare, physically disabling conditions who may not traditionally have easy access to meeting others with similar NMD experiences. The sharing of aspirations for the group to develop as a "powerful resource" and a fun and sociable group appeared to be an instrumental part of setting the conversational tone. This sharing of dual aspirations suggests that participants in the group hoped it would be an important individual information source but also a strong collective knowledge base with supportive and social functions. Due to the rare nature of many NMDs, such a forum could have a potentially important role as a mechanism for sharing and gaining information on rare illness/symptom experiences, empowering individuals and family members in relation to self-management. Moderators' efforts to 
welcome and support new members, as well as encouraging participation, echoes findings from recent research with online support group moderators who describe part of their role as nurturing a safe online environment [52].

Members found it difficult to access medical advice and expertise especially in relation to diagnosis and distressing symptoms and used the message board to seek validation of their experiences. Consistent with previous research on online support groups in other health conditions $[50,53]$, members used the group to exchange experiences on symptoms and coping. Members particularly discussed anxiety and sadness related to symptoms and illness progression, echoing previous research which has highlighted the fear and uncertainty experienced by those with progressive NMDs $[8,9]$ and the regret associated with declining ability to participate in valued activities [7]. In line with previous online support group research, members shared support and empathy, using their personal experiences to support others [39,40,54] and normalise illness experiences [55]. Support group members encouraged each other to maintain a positive outlook. Whilst this is a not an uncommon support mechanism in such groups [56,57], encouragement in this group mainly focused on resilience in fighting for services and adaptations and acceptance of any aids or adaptations that may be needed for condition management.

Many individuals on this board sought information and/or validation regarding symptoms. The group provided a mechanism for members to discuss symptoms that were new or unusual with other members. This may be an important function of such groups for individuals who struggle with medical recognition of symptoms or are experiencing symptoms that are quite unique or specific to rare types of NMDs. Emotional validation regarding the impact of progressive symptoms is a potentially important function of the group. Members were 
reassured regarding their experiences of numerous emotional reactions and also encouraged one another to remain positive and to fight for any resources they needed to help them or their family members to manage. The sharing of practical suggestions on symptom management and adjusting to life with NMD also indicated how the group had begun to take on both informational and social support elements which may help empower individual members.

An unanticipated finding was members' use of the board to discuss societal and political issues relating to living with NMDs. Members discussed problems in relation to recognition of their illness which resonates with previous reports of the difficulties people with NMD have in terms of dealing with public misconceptions of their symptoms $[9,10]$. Negative media and Government portrayals of disabled people were described as a source of stress. The political climate of cuts to welfare payments created worry among members about maintaining their quality of life and independence, highlighting the need for clear advice and support for people affected by such policy changes. Members discussed and advocated varied approaches to raising awareness about NMDs which may be particularly important due to the rarity of many of these conditions. Political activism has been noted in other health-related online support groups [58] and collective action has been identified as a potentially empowering outcome of participation [54]. In this case, collective action was realised through participation in surveys and protests, sharing information, and writing letters to Government representatives that raised the profile of NMDs beyond the group. Therefore, the group can be seen as potentially giving members opportunities for individual empowerment though information provision, as well as sharing support and self-management strategies, but also by providing a more collective voice for members to challenge social and political realities of living with a rare NMD. 
The strengths of this study lie in the exploration of an under-researched phenomenon; that of the use of online support groups in NMDs. The use of naturalistic data from message posts allowed us to gain an understanding of the natural conversational processes on a new online support group, without disturbing the discursive flow of members' conversations. The findings validate previous findings from other health-related online support group research studies but also demonstrate important novel insights into how people affected by rare, often progressive disorders may use such groups.

There are, however, limitations to the current study. The data collected in this study represent the experiences of a select group of individuals using one particular NMD online support group. Little is known about the demographic characteristics of members included in this study. Therefore, it is difficult to examine how representative they are of the wider population of individuals and families affected by NMDs. The findings gleaned cannot be said to represent the experiences of all those with NMDs and all those people with NMDs who use different online support groups. The use of message posts as data also necessarily excludes the views of non-posting members of the group [54,59] which limits our understanding of the experiences of those who use the group to just those who actively participate in posting messages.

A further limitation is that the current analysis may also be influenced by specific group dynamics such as the influences of group moderators or dominant contributors [59]. The support group was hosted by a charitable organisation based in the U.K., which may have influenced the types of contributors who participated in the group and the types of messages posted. The group may have been influenced by the specific political goals of the charity. 
Therefore, it cannot be claimed that the discussion processes and content here would mimic those in other NMD online support groups, including those led by people with NMDs or their carers, or that are based in different countries. The messages analysed were also taken from the first five months of messages to this particular group which means the analysis is limited to a presentation of the formation of this group. It may be that individuals' use of more established groups differ. Therefore, there is a need for further research across different NMD online support groups and over longer periods of time to further verify and extend upon the findings of this study.

The use of message postings, whilst providing an extensive naturalistic account of member interactions on the support group, free from influence by researchers, is limited as a method of gaining insight into participant experiences. In order to extend upon the findings here, it would also be beneficial to examine participant experiences using different participatory data collection methods (e.g. interviews and questionnaires) so that members can reflect directly on their motivations for using the group, their evaluations of their online experiences and any potential positive or negative effects of participation.

In conclusion, this study demonstrates that online support groups for people affected by NMDs may have an important role in allowing people with rare disorders to make contact with others with similar conditions and symptom experiences in order to gain understanding of, and to normalise, their illness experiences. Such groups may also afford members opportunities to discuss emotional aspects of the condition as well as share support on coping and maintaining a positive outlook. Online support groups may also provide an opportunity 
for people with rare disorders to raise awareness of their condition and to discuss political and social influences on living with long-term physical illnesses.

Declaration of interest: This study was funded by a $\mathrm{PhD}$ studentship awarded to the first author by the University of Nottingham.

\section{References}

1. Hilton-Jones D, Freebody J, Stein J. Neuromuscular Disorders in the Adult : A Practical Manual. Oxford: Oxford University Press; 2011.

2. Pohlschmidt M, Meadowcroft R. Muscle Disease: The Impact, Incidence and Prevalence of Neuromuscular Conditions in the UK. London: Muscular Dystrophy Campaign; 2010.

3. Norwood FL, Harling C, Chinnery PF, Eagle M, Bushby K, Straub V. Prevalence of genetic muscle disease in Northern England: in-depth analysis of a muscle clinic population. Brain. 2009;132(Pt 11):3175-3186.

4. Boström K, Nätterlund BS, Ahlström G. Sickness impact in people with muscular dystrophy: a longitudinal study over 10 years. Clinical Rehabilitation. 2005;19(6):686-694.

5. Dahlbom K, Ahlström G, Barany M, Kihlgren A, Gunnarsson LG. Muscular dystrophy in adults: a five-year follow-up. Scandinavian Journal of Rehabilitation Medicine.

1999;31(3):178-184.

6. Grootenhuis MA, de Boone J, van der Kooi AJ. Living with muscular dystrophy: health related quality of life consequences for children and adults. Health and Quality of Life Outcomes. 2007;5:31.

7. Boström K, Ahlström G. Living with a chronic deteriorating disease: the trajectory with muscular dystrophy over ten years. Disability and Rehabilitation. 2004;26(23):1388-1398.

8. Boström K, Ahlström G. Living with a hereditary disease: persons with muscular dystrophy and their next of kin. American Journal of Medical Genetics. Part A. 2005;136(1):17-24.

9. Krause-Bachand J, Koopman W. Living with oculopharyngeal muscular dystrophy: a phenomenological study. Canadian Journal of Neuroscience Nursing. 2008;30(1):35-39.

10. Sadjadi R, Vincent KA, Carr AJ, Walburn J, Brooks VL, Pandya S, Kissel JT, Jackson CE, Rose MR, Group MS. Validation of the individualised neuromuscular quality of life for the USA with comparison of the impact of muscle disease on those living in USA versus UK. 
Health and Quality of Life Outcomes. 2011;9:114.

11. Winblad S, Jensen C, Månsson E. J, Samuelsson L, Lindberg C. Depression in Myotonic Dystrophy type 1: clinical and neuronal correlates. Behavioral and Brain Functions. 2010;6:25.

12. Graham CD, Rose MR, Grunfeld EA, Kyle SD, Weinman J. A systematic review of quality of life in adults with muscle disease. Journal of Neurology. 2011;258(9):1581-1592.

13. Webb CL. Parents' perspectives on coping with Duchenne muscular dystrophy. Child: Care Health and Development. 2005;31(4):385-396.

14. Plumridge G, Metcalfe A, Coad J, Gill P. Family communication about genetic risk information: particular issues for Duchenne muscular dystrophy. American Journal of Medical Genetics. Part A. 2010;152A(5):1225-1232.

15. Boström K, Ahlström G, Sunvisson H. Being the next of kin of an adult person with muscular dystrophy. Clinical Nursing Research. 2006;15(2):86-104.

16. Mah JK, Thannhauser JE, McNeil DA, Dewey D. Being the lifeline: the parent experience of caring for a child with neuromuscular disease on home mechanical ventilation. Neuromuscular Disorders. 2008;18(12):983-988.

17. Samson A, Tomiak E, Dimillo J, Lavigne R, Miles S, Choquette M, Chakraborty P, Jacob $P$. The lived experience of hope among parents of a child with Duchenne muscular dystrophy: perceiving the human being beyond the illness. Chronic Illness. 2009;5(2):103114.

18. Nereo NE, Fee RJ, Hinton VJ. Parental stress in mothers of boys with duchenne muscular dystrophy. Journal of Pediatric Psychology. 2003;28(7):473-484.

19. Reid DT, Renwick RM. Relating familial stress to the psychosocial adjustment of adolescents with Duchenne muscular dystrophy. International Journal of Rehabilation Research. 2001;24(2):83-93.

20. Abi Daoud MS, Dooley JM, Gordon KE. Depression in parents of children with Duchenne muscular dystrophy. Pediatric Neurology. 2004;31(1):16-19.

21. Lamb C, Peden A. Understanding the experience of living with spinal muscular atrophy: a qualitative description. The Journal of Neuroscience Nursing. 2008;40(4):250-256.

22. Miró J, Raichle KA, Carter GT, O’Brien SA, Abresch RT, McDonald CM, Jensen MP. Impact of biopsychosocial factors on chronic pain in persons with myotonic and facioscapulohumeral muscular dystrophy. The Amercian Journal of Hospice \& Palliative Care. 2009;26(4):308-319.

23. Raggi A, Leonardi M, Mantegazza R, Casale S, Fioravanti G. Social support and selfefficacy in patients with Myasthenia Gravis: a common pathway towards positive health 
outcomes. Neurological Sciences. 2010;31(2):231-235.

24. Nätterlund B, Ahlström G. Experience of social support in rehabilitation: a phenomenological study. Journal of Advanced Nursing. 1999;30(6):1332-1340.

25. Wenneberg S, Gunnarsson LG, Ahlström G. Using a novel exercise programme for patients with muscular dystrophy. Part I: a qualitative study. Disability and Rehabilitation. 2004;26(10):586-594.

26. Hartley SE, Goodwin PC, Goldbart J. Experiences of attendance at a neuromuscular centre: perceptions of adults with neuromuscular disorders. Disability and Rehabilitation. 2011;33(12):1022-1032.

27. Han HR, Belcher AE. Computer-mediated support group use among parents of children with cancer - an exploratory study. Computers in Nursing. 2001;19(1):27-33.

28. Coulson NS, Knibb RC. Coping with food allergy: exploring the role of the online support group. Cyberpsychology \& Behavior. 2007;10(1):145-148.

29. Davison KP, Pennebaker JW, Dickerson SS. Who talks? The social psychology of illness support groups. American Psychologist. 2000;55(2):205-217.

30. Klemm P, Nolan MT. Internet cancer support groups: legal and ethical issues for nurse researchers. Oncology Nursing Forum. 1998;25(4):673-676.

31. Preece J, Nonnecke B, Andrews D. The top five reasons for lurking: improving community experiences for everyone. Computers in Human Behavior. 2004;20:201-223.

32. Wright K. Perceptions of on-line support providers: an examination of perceived homophily, source credibility, communication and social support within on-line support groups. Communication Quarterly. 2000;48(1):44-59.

33. Sandaunet AG. The challenge of fitting in: non-participation and withdrawal from an online self-help group for breast cancer patients. Sociology of Health \& Illness. 2008;30(1):131-144.

34. Coulson NS, Greenwood N. Families affected by childhood cancer: an analysis of the provision of social support within online support groups. Child: Care Health and Development. 2012;38(6):870-877.

35. Pfeil U, Zaphiris P, Wilson S. Older adults' perceptions and experience of online social support. Interacting with Computers. 2009;21:159-172.

36. Van Uden-Kraan CF, Drossaert CHC, Taal E, Lebrun CI, Drossaers-Bakker KW, Smit WM, Seydel ER, Van de Laar MAF. J. Coping with somatic illnesses in online support groups: Do the feared disadvantages actually occur? Computers in Human Behavior. 2008;24:309-324.

37. Esquivel A, Meric-Bernstam F, Bernstam E V. Accuracy and self correction of 
information received from an internet breast cancer list: content analysis. British Medical Journal. 2006;332:939-942.

38. Braithwaite DO, Waldron VR, Finn J. Communication of social support in computermediated groups for people with disabilities. Health Communication. 1999;11(2):123-151.

39. Malik S, Coulson NS. The therapeutic potential of the internet: exploring self-help processes in an internet forum for young people with inflammatory bowel disease.

Gastroenterology Nursing. 2011;34(6):439-448.

40. Perron B. Online support for caregivers of people with a mental illness. Psychiatric Rehabilitation Journal. 2002;26(1):70-77.

41. White M, Dorman SM. Receiving social support online: implications for health education. Health Education Research. 2001;16(6):693-707.

42. Coulson NS, Buchanan H, Aubeeluck A. Social support in cyberspace: a content analysis of communication within a Huntington's disease online support group. Patient Education and Counseling. 2007;68:173-178.

43. Coulson NS. Receiving social support online: an analysis of a computer-mediated support group for individuals living with irritable bowel syndrome. Cyberpsychology \& Behavior. 2005;8(6):580-584.

44. Soutter J, Hamilton N, Russell P, Russell C, Bushby K, Sloper P, Bartlett K. The Golden Freeway: a preliminary evaluation of a pilot study advancing information technology as a social intervention for boys with Duchenne muscular dystrophy and their families. Health and Social Care in the Community. 2004;12(1):25-33.

45. Sixsmith J, Murray CD. Ethical issues in the documentary data analysis of internet posts and archives. Qualitative Health Research. 2001;11(3):423-432.

46. Malik SH, Coulson NS. Coping with infertility online: an examination of self-help mechanisms in an online infertility support group. Patient Educucation and Counseling. 2010;81(2):315-318.

47. Braun V, Clarke V. Using thematic analysis in psychology. Qualitative Research in Psychology. 2006;3(2):77-101.

48. Tichon JG, Shapiro M. The process of sharing social support in cyberspace.

Cyberpsychology \& Behavior. 2003;6(2):161-170.

49. Pfeil U, Zaphiris P, Wilson S. The role of message-sequences in the sustainability of an online support community for older people. Journal of Computer-Mediated Communication. 2010;15:336-363.

50. Armstrong N, Koteyko N, Powell J. "Oh dear, should I really be saying that on here?": issues of identity and authority in an online diabetes community. Health. 2012;16(4):347- 
365.

51. Stommel W, Meijman FJ. The use of conversation analysis to study social accessibility of an online support group on eating disorders. Global Health Promotion. 2011;18(2):18-26.

52. Coulson NS, Shaw RL. Nurturing health-related online support groups: Exploring the experiences of patient moderators. Computers in Human Behavior. 2013;29(4):1695-1701.

53. Springer A, Reck CA, Huber C, Horcher E. Online hypospadias support group data analysis. Journal of Pediatric Surgery. 2011;46(3):520-524.

54. van Uden-Kraan CF, Drossaert CH, Taal E, Shaw BR, Seydel ER, van de Laar MA. Empowering processes and outcomes of participation in online support groups for patients with breast cancer, arthritis, or fibromyalgia. Qualitative Health Research. 2008;18(3):405417.

55. Cranwell J, Seymour-Smith S. Monitoring and normalising a lack of appetite and weight loss. A discursive analysis of an online support group for bariatric surgery. Appetite. 2012;58(3):873-881.

56. Attard A, Coulson NS. A thematic analysis of patient communication in Parkinson's disease online support group discussion forums. Computers in Human Behavior. 2012;28:500-506.

57. Cunningham JA, van Mierlo T, Fournier R. An online support group for problem drinkers: AlcoholHelpCenter.net. Patient Education and Counseling. 2008;70(2):193-198.

58. Peterson JL. "You have to be positive." Social support exchanges of an online support group for men living with HIV/AIDS. Communication Studies. 2009;60(5):526-541.

59. Murray CD, Sixsmith J. Qualitative health research via the internet: practical and methodological issues. Health Informatics Journal. 2002;8(1):47-53. 


\begin{tabular}{|c|c|c|c|}
\hline Themes & Sub-themes & Codes & \\
\hline \multirow[t]{3}{*}{$\begin{array}{l}\text { 1. Connecting } \\
\text { and sharing }\end{array}$} & $\begin{array}{l}\text { 1.1 Establishing common } \\
\text { ground }\end{array}$ & $\begin{array}{l}1.1 .1 \\
1.1 .2 \\
1.1 .3 \\
1.1 .4\end{array}$ & $\begin{array}{l}\text { Disclosing personal information } \\
\text { Connecting with similar others } \\
\text { "Make yourself at home" } \\
\text { Sharing aspirations for OSG development }\end{array}$ \\
\hline & $\begin{array}{l}\text { 1.2 Sharing diagnosis } \\
\text { experiences }\end{array}$ & $\begin{array}{l}1.2 .1 \\
1.2 .2 \\
1.2 .3 \\
1.2 .4\end{array}$ & $\begin{array}{l}\text { Introducing relationship to NMDs } \\
\text { Diagnostic delay } \\
\text { Sharing negative emotional reactions to diagnosis } \\
\text { Sharing relief at eventual diagnosis }\end{array}$ \\
\hline & 1.3 Sharing diagnosis support & $\begin{array}{l}1.3 .1 \\
1.3 .2 \\
1.3 .3 \\
1.3 .4\end{array}$ & $\begin{array}{l}\text { Validating members' experiences } \\
\text { Validating members' emotions } \\
\text { Comforting and supporting members } \\
\text { Signposting to support and information sources }\end{array}$ \\
\hline \multirow[t]{3}{*}{$\begin{array}{l}\text { 2. 'An } \\
\text { understanding } \\
\text { audience' }\end{array}$} & $\begin{array}{l}2.1 \text { Collective symptom } \\
\text { interpretation }\end{array}$ & $\begin{array}{l}2.1 .1 \\
2.1 .2 \\
2.1 .3 \\
2.1 .4\end{array}$ & $\begin{array}{l}\text { Sharing symptoms } \\
\text { "Does anyone else feel this way?" } \\
\text { Sharing knowledgelexperience of similar } \\
\text { symptoms } \\
\text { Encouraging medical advice seeking }\end{array}$ \\
\hline & $\begin{array}{l}2.2 \text { Emotional reactions to } \\
\text { symptoms }\end{array}$ & $\begin{array}{l}2.2 .1 \\
2.2 .2 \\
2.2 .3 \\
2.2 .4 \\
2.2 .5 \\
2.2 .6\end{array}$ & $\begin{array}{l}\text { Anxiety about symptoms } \\
\text { Regret at declining functional ability } \\
\text { Feeling unsupported in the medical management } \\
\text { of symptoms } \\
\text { Reluctance to use aids/adaptations } \\
\text { Maintaining a positive outlook } \\
\text { Valuing support from close friends and family }\end{array}$ \\
\hline & $\begin{array}{l}2.3 \text { Supporting one another with } \\
\text { condition management }\end{array}$ & $\begin{array}{l}2.3 .1 \\
2.3 .2 \\
2.3 .3 \\
2.3 .4 \\
2.3 .5\end{array}$ & $\begin{array}{l}\text { Sharing information } \\
\text { Validating feelings regarding symptoms } \\
\text { Reassuring members of available mutual support } \\
\text { Encouraging a positive outlook } \\
\text { Encouraging a pro-active attitude to support } \\
\text { seeking }\end{array}$ \\
\hline \multirow[t]{3}{*}{$\begin{array}{l}\text { 3. Recognition } \\
\text { and awareness }\end{array}$} & $\begin{array}{l}\text { 3.1 Sharing difficulties } \\
\text { regarding NMD recognition }\end{array}$ & $\begin{array}{l}3.1 .1 \\
3.1 .2 \\
3.1 .3\end{array}$ & $\begin{array}{l}\text { Facing poor professional understanding } \\
\text { Contending with public misconceptions } \\
\text { Feeling misrepresented by government and media }\end{array}$ \\
\hline & $\begin{array}{l}\text { 3.2 Fostering discussion on } \\
\text { political, societal and healthcare } \\
\text { issues }\end{array}$ & $\begin{array}{l}3.2 .1 \\
3.2 .2\end{array}$ & $\begin{array}{l}\text { "Have you heard?" } \\
\text { Sharing concerns and hopes regarding political } \\
\text { change }\end{array}$ \\
\hline & 3.3 Raising awareness & $\begin{array}{l}3.3 .1 \\
3.3 .2 \\
3.3 .3 \\
3.3 .4\end{array}$ & $\begin{array}{l}\text { Raising awareness through educating others } \\
\text { Raising awareness through campaigning } \\
\text { Valuing volunteer and charity support in } \\
\text { championing issues } \\
\text { Valuing research in terms of hopes for the future }\end{array}$ \\
\hline
\end{tabular}

Table 1: Thematic map 
